\title{
BMJ Open Relationship between role stressors, job tasks and job satisfaction among health surveillance assistants in Malawi: a cross-sectional study
}

\author{
Simon Ntopi (D) , ${ }^{1}$ Ellen Chirwa, ${ }^{2}$ Alfred Maluwa ${ }^{3}$
}

To cite: Ntopi S, Chirwa E, Maluwa A. Relationship between role stressors, job tasks and job satisfaction among health surveillance assistants in Malawi: a crosssectional study. BMJ Open 2020;10:e037000. doi:10.1136/ bmjopen-2020-037000

- Prepublication history for this paper is available online. To view these files, please visit the journal online (http://dx.doi. org/10.1136/bmjopen-2020037000).

Received 19 January 2020 Revised 12 September 2020 Accepted 15 October 2020

Check for updates

(c) Author(s) (or their employer(s)) 2020. Re-use permitted under CC BY-NC. No commercial re-use. See rights and permissions. Published by BMJ.

${ }^{1}$ Faculty of Applied Health Studies, University of Malawi Kamuzu College of Nursing, Lilongwe, Malawi

${ }^{2}$ Faculty of Applied Health Studies, University of Malawi, The Kamuzu College of Nursing, Lilongwe, Malawi

${ }^{3}$ Department of Postgraduate Studies and Outreach, Malawi University of Science and Technology, Limbe, Malawi

Correspondence to

Dr Simon Ntopi;

sntopi892@gmail.com

\section{ABSTRACT}

Objectives The objective of this study was to investigate the role stressors, sociodemographic characteristics and job tasks of health surveillance assistants (HSAs) and to explore major predictors of role stressors and job satisfaction of HSAs in Malawi.

Setting Data were collected from health centres and hospitals of three Malawi districts of Mangochi, Lilongwe and Mzimba.

Participants Respondents were 430 HSAs. $50.20 \%$ of them were male, while $49.8 \%$ were female.

Design A cross-sectional study of the observational correlational design was carried out.

Main outcome measures Respondents perceptions of job tasks, role stressors and job satisfaction.

Results The key findings of this study were role ambiguity and role overload were significantly negatively related to job satisfaction, while role conflict was insignificantly related to job satisfaction. Additionally, the clinical tasks of the HSAs and some of the sociodemographic variables were associated with the role stressors and job satisfaction of the HSAs in Malawi.

Conclusions Since the HSAs clinical tasks were significantly related to all role stressors, there is need by the government of Malawi to design strategies to control the role stressors to ensure increased job performance and job satisfaction among HSAs. Furthermore, studies may be required in the future to assist government to control role stressors among HSAs in Malawi.

\section{INTRODUCTION}

In Malawi, there is a critical shortage of health workers where the doctor/patient ratio is as low as three doctors per 100000 people, lower than the WHO's prescribed norm of one doctor for 1000 people. Additionally, there has been a growing demand for healthcare in Malawi especially with the advent of the HIV/AIDS pandemic. ${ }^{1}$ To meet this high demand for healthcare, task shifting has been advocated where some of the roles of medical doctors have been delegated to junior cadres such as clinical officers and health surveillance assistants (HSAs). Task shifting is the delegation of tasks to people
Strengths and limitations of this study

- We used adequate statistical analysis to relate role stressors and job satisfaction in health surveillance assistants (HSAs)

- We adapted instruments that have commonly been used and have high reliability in studies related to role stressors and job satisfaction.

- The study is limited in that it only considers data from HSAs working in government under government pay roll being studied.

- Additionally, the study is limited in terms of literature, because it is the first of its kind to be conducted among HSAs.

- The study being a cross-sectional study did not elicit much information about the role stressors in HSAs.

who are in lower positions. ${ }^{23}$ Its implementation is wholly supported by the WHO, which recommends each country introducing task shifting through community health workers (CHWs) should have a national framework to guide the roles and training of $\mathrm{CHWs} .^{3}$

The HSA cadre has its routes from the Alma Ata Declaration in Russia in 1978. ${ }^{4}$ The meeting was a high-level global meeting organised by the WHO and UNICEF. ${ }^{5}$ The meeting was attended by official government representatives from all over the world and UNICEF member countries. At the meeting, the role of the CHW was well defined. Formerly, they were known as smallpox vaccinators or cholera assistants and were renamed HSAs immediately after the Alma Ata Declaration. ${ }^{6}$ HSAs are a group of one of the community-based health workers in Malawi. Historically, the role of the HSAs focused mainly on the delivery of preventive health services such as hygiene and sanitation promotion, immunisation, and health education. ${ }^{6}$ Since then, the HSAs' role has expanded to include roles such as community-based maternal and newborn 
care, child health, nutrition and family planning, all of which are delivered under the essential health package programme. $^{7}$

With this expanded role, there is a general feeling among HSAs and other health workers that the HSAs are overloaded with work. ${ }^{8}$ In terms of role ambiguity, issues such as the absence of standardised procedures for their selection and training have been featured including lack of job descriptions and work protocols for their use at work. ${ }^{10}$ Regarding role overload, HSAs have the feeling that they are doing too much and that they are overloaded with work. ${ }^{11}$ In terms of role conflict, the HSAs' role overlaps with the roles of other cadres such as nurses, clinical officers and assistant environmental health officers (AEHOs). Additionally, their supervision is complex as it involves many supervisors from both clinical and the preventive section; and in the course of this, role conflict arises due to competing priorities. ${ }^{11}$ All this has the likelihood to contribute towards high role overload, lower work performance and lower job satisfaction. $^{12}$

Role stressors in the literature often times have referred to the terms such as role conflict, role ambiguity and role overload. ${ }^{13}$ Role conflict among HSAs could refer to conflicting situations that may arise at the workplace and may affect their compliance. ${ }^{14}$ An example of this could be a conflicting situation that may arise between the HSAs and their supervisors or coworkers at the workplace. A very likely example of this is a situation where an HSA reports to two supervisors; one supervisor may need the HSA while the HSA is busy with the other supervisor. Situations like this are likely to cause role conflict at the workplace. Role ambiguity is defined as when employees lack some clarity on their roles. ${ }^{14}$ A good example of this could be the introduction of a new role without proper orientation or guidelines for the workers. Role overload is defined as when employees have too many roles or tasks to perform. ${ }^{14}$ This is likely to happen when employees do not have adequate time for them to perform other roles such as those related to work or family because they have too many roles.

Generally, information about the CHWs' role ambiguity, role conflict, role overload and job satisfaction are scanty in the literature. Studies have been conducted elsewhere in the developed or developing countries in Asia $^{1516}$ on other professions such as nurses, accounting personnel and teachers. The studies conducted measured role stressors such as role ambiguity, role conflict and role overload and have suggested that if these role stressors remain uncontrolled, they will affect the job performance and the job satisfaction of employees in an organisation. ${ }^{17}$ This current study was specifically aimed to explore: (1) perceptions of HSAs on role stressors and job satisfaction, (2) the effect of job tasks and sociodemographic characteristics on the role stressors and job satisfaction and (3) identify the main predictors of role stressors and job satisfaction.

\section{THEORETICAL FRAMEWORK}

The Role Episode Model (REM) by Katz and $\mathrm{Kahn}^{18}$ was integrated with the job satisfaction theories to further explore role conflict, role ambiguity, role overload and job satisfaction of HSAs. The model suggests factors such as organisational (ie, formal power structure, level in the organisation, role requirements, task characteristics, physical setting and organisational practices) and personal and interpersonal factors (ie, individual's status, needs, values, education, ability, age, sex or gender and tenure) affect the communication process in the REM. The model was used to identify predictors associated with role stressors and job satisfaction in the management of stress.

Role theory states that when the behaviours expected of an individual are inconsistent, there is likely to be role conflict that may lead to stress and eventually get the employee dissatisfied with the job and have lower work performance. ${ }^{19} 20$ Additionally, the theory states that the absence of information such as work guidelines can contribute to role ambiguity and job dissatisfaction as the employee tries to develop coping mechanisms and a defensive mechanism to avoid stress. ${ }^{21}$ In line with what has been stipulated previously, this study suggests HSAs occupy a role, and this role is accompanied by expected and perceived behaviours and actions that are applicable to the successful performance of their role. ${ }^{22}$

Herzberg's motivator-hygiene theory of job satisfaction was also applied in the study. Factors such as achievement, recognition, advancement, compensation, authority, responsibility and the job itself were considered as motivational factors (intrinsic job satisfaction), while organisation policies and practices, supervision, relationship with coworkers, job security, social status and work conditions were considered as hygiene factors (extrinsic satisfaction). ${ }^{23}$ In line with this view, it was our assumption that HSAs are satisfied with motivational factors and are dissatisfied with hygiene factors.

\section{METHOD}

\section{Study design and sample}

Between January 2017 and December 2017, a crosssectional survey was conducted to investigate the relationship between role stressors, job tasks and job satisfaction among HSAs in Malawi. Data were collected from HSAs working in three districts of Mangochi, Lilongwe and Mzimba South, which represented the southern, central and northern regions of Malawi, respectively. Lilongwe district had both urban and rural representation. The urban setting was selected for comparison if there were any differences in the role stressors and job satisfaction between the rural HSAs and the urban HSAs.

All HSAs working in the three selected districts under the government of Malawi payroll and working in either Christian Hospitals Association of Malawi (CHAM) or Ministry of Health facilities and had work experience of 2 or more years were eligible to participate in the study. 
Overall, the population of HSAs in the three districts was 1924 and 9 did not meet the inclusion criteria. The sample size for the study was 385 HSAs and was calculated based on Lemeshow et $a l^{24}$ sample size calculation formula for a cross-sectional study. Since studies to explore role stressors and job satisfaction of HSAs had not been conducted in Malawi, it was assumed that $50 \%$ of the HSAs were affected by the phenomena. Twenty per cent was factored in considering the rate of the nonresponses. A total number of 462 questionnaires were distributed, and the response rate was $93.5 \%$. Multistage sampling was done at national level to select districts and at district level to select health facilities. This was done to ensure there was no bias and the study results were representative.

Prior to the data collection, the questionnaire was reviewed by experts in the field and some HSAs to ensure it had the right content. A pilot test was conducted in Nkhotakota, a district different from the sampled districts among 36 HSAs (data not included in the final analysis). The district health officers $p$ were asked for permission to distribute the questionnaire within their health facilities (health centres and hospitals). Health facilities with high number of HSAs population were selected using probability proportional to size sampling. The research assistants gave an explanation of the research that all the information provided would be used anonymously. Participation was voluntary, considering that neither patients nor patients' data were involved in the study. Additionally, participants were asked to sign a consent form before responding to the questionnaire. The study used a descriptive cross-sectional study design, and this decision was based on the fact that it was appropriate for exploring the relationships that exist between the HSAs tasks, role stressors and job satisfaction at a single given point in time. ${ }^{25}$

\section{Patient and public involvement statement}

Patients and public were not involved in the development, design, recruitment and sampling of this study.

\section{Measures}

A standardised face-to-face self-administered questionnaire having five sections was used to measure study variables. The first section collected sociodemographic data with the intention to identify if there were some confounding variables that play a role in the relationship between role stressors and job satisfaction. Subsequent sections collected data on HSAs' job tasks (as taken from the HSAs' job description), role conflict and role ambiguity, role overload and job satisfaction using adapted instruments. To adapt some items for the questionnaires, permission was sought from the American Psychological Association and the University of Minnesota Vocational Psychology Research through the RightsLink of the Copyright Clearance Centre.

A profile of HSAs was created from the data, and the sociodemographic information such as age, sex, level of education and years at service post was reported. Descriptive statistics such as mean, corresponding SD and percentages formed some of the summary statistics.

Role conflict and ambiguity was measured by role conflict and ambiguity (RCA) scale developed by Rizzo et $a .^{26}$ The scale in total had 14 items: six items for role ambiguity and eight items for role conflict. The scale was a 5-point Likert-type response format (from 1='strongly disagree' and $5=$ 'strongly agree'). The RCA scale was chosen because it has been widely used in literature and is the most dominant tool used in role conflict and role ambiguity studies. ${ }^{27} 28$ Role conflict scores for the sample were calculated to get a mean with its SD and range. The possible range of role conflict scores with the tool used was 1.00-5.00. A higher number denoted a higher rate of role conflict. Similarly, role ambiguity scores were calculated to get a mean with its SD and range. The possible range of role ambiguity scores using the tool was 1.00-5.00.

Role overload was measured by the use of the Role Overload Scale (ROS) developed by Reilly. ${ }^{29}$ The ROS is a 13-item questionnaire ("there are too many demands on my time') with a 5-point Likert-type response format (from $1=$ 'strongly disagree' and $5=$ ='strongly agree'). The tool had a Cronbach's alpha of 0.88. Other researchers had found the Cronbach's alpha ranging from 0.89 to $0.94 .^{30-32}$ Role overload scores for the sample were calculated to get a mean with its SD and range. The possible range of role overload scores with the scale used was 1.005.00 , with the higher score denoting a higher rate of role overload, and the possible range of role overload scores using the scale was 1.00-5.00.

The Minnesota Satisfaction Questionnaire (MSQ) of the shorter version, the MSQ20, was used to collect data on job satisfaction. The tool had been widely used in both developed and developing countries. ${ }^{33}$ It is a 20 -item questionnaire with a 5-point Likert-type response format (from $1=$ very dissatisfied to 5 =very satisfied). The instrument is also reported to have high Cronbach's alpha ranging between 0.70 and $0.80 .{ }^{34}$

Job satisfaction scores for the sample were calculated to get a mean with its SD and range. The possible range of job satisfaction scores with the scale used was $1.00-5.00$, with the higher score denoting a higher rate of job satisfaction. The possible range of job satisfaction scores using the scale was $1.00-5.00$.

The task inventory scale developed by Burgel $e t a l^{35}$ was adapted in this study to collect information on HSAs' job tasks. The instrument has been used in previous studies by Mbambo $e t a l^{36}$ and Uys $e t a l^{37}$ in studies related to job analysis of selected health workers in a district health system in KwaZulu-Natal for the South African Primary Health Care (PHC) package of services. The instrument was modified, and tasks not relevant to this study were removed and replaced with HSAs' tasks contained in their job description to develop a final instrument. For each task, two options were required: to tick in the most appropriate box whether the task applied to the setting and the frequency with which the task was carried out 
(less than once per week, 1-5 times per week, 6-10 times per week and more than 10 times per week). In addition, the questionnaire had a demographic section where all information pertaining to demographic variables were collected.

The data collection tools were first pretested before distribution to respondents. The pretest was done among HSAs in Nkhotakota, a different district from the sampled districts. The pretest was conducted with the intention to identify items in the questionnaire that were not clearly drafted and might not be clear in the reader's view. The identified items were corrected and once the corrections were made, the questionnaire was ready for distribution to the respondents. The pretest findings were not incorporated into the main study.

Internal consistency was used to assess the reliability of the scales and subscales. This was carried out to find out if there was consistency in the way the respondents responded to the items on the questionnaire. Cronbach's alpha $(\alpha)$ was used for this purpose. The RCA, the ROS and the MSQ scales had all a Cronbach's alpha of $\geq 0.70$. Originally, the authors had high Cronbach's alpha ranging from 0.80 to 0.90 , but this was deemed acceptable since the instruments were adapted with some minor modifications and translated into the vernacular language (Chichewa), which is commonly spoken in most districts in Malawi. The Cronbach's alpha for the Task Inventory Scale was 0.60 . An alpha value of $\geq 0.70$ is desirable, although values that are slightly below 0.70 are usually considered acceptable. ${ }^{38}$

Content validity was used to ensure that the instrument captured relevant information and it measured role stressors and job satisfaction in all HSAs in a similar manner to avoid bias. ${ }^{39}$ Experts in the field were given the questionnaire to look at the items to determine whether the items in the scale accurately reflected the constructs of role stressors and job satisfaction and the HSAs' tasks. Additionally, validity was achieved by bias control through multistage sampling that ensured all the three regions of the country, districts, health facilities and the HSAs in the sampled districts had an equal chance of representation. Furthermore, the researcher ensured that all questionnaire items were based on the objectives of the study. ${ }^{40}$

Permission to use the instruments was sought from the owners before use. The questionnaire was translated into the vernacular language (Chichewa) and back translated into English for consistency of meaning. The translation process for the questionnaire from English to the vernacular language (Chichewa) followed a method as illustrated by $\mathrm{WHO}^{41}$ and involved both forward and back translation to ensure there was the consistency of meaning.

The data analysis involved the use of statistics such as mean scores, $\mathrm{SD}, \chi^{2}$, principal component analysis (PCA) and multiple regression. More details on their use have been provided in the subsequent subsections of this study.
To ascertain if there was a relationship between role conflict or role ambiguity and job satisfaction, a Pearson product-moment coefficient $r$ was used. The possible range of correlation coefficients is -1 and +1 . A coefficient of +1 indicated that the two variables were positively correlated, while a coefficient of -1 indicated a negative relationship between the study variables.

Similarly, a Pearson product-moment coefficient $r$ was used to ascertain if there was a relationship between role overload and job satisfaction. The possible range of correlation coefficients is -1 and +1 . A coefficient of +1 indicated that the two variables were positively correlated while a coefficient of -1 indicated a negative relationship between the study variables.

The PCA analysis was conducted using SPSS Statistics V.23 with principal axis factoring to examine the psychometric properties of the measures. The approach employed maximum likelihood extraction and varimax rotation with Kaiser normalisation to ascertain the dimensions underlying the research construct. The Kaiser rule and scree test were used to measure sampling adequacy, and the decision was based on the Kaiser-Meyer-Olkin (KMO) $>0.60$, which is recommended in social sciences. ${ }^{42}$ The criterion for retaining factors was an eigenvalue $>1$. Items were considered to contribute sufficiently to a factor when their loading was $0.70 .^{43}$ The Bartlett's test was conducted to ensure it had a statistically significant probability of $(p \leq 0.001)$. Subsequent rotation was used to show interrelationships between factors. The Pearson's product-moment correlation was used to assess the main items of the dependent variables and to assess relationships between the dependent variables. Appended in table 1 is the KMO and Bartlett's test results.

\section{RESULTS}

A total of 432 responses were received. Data from two participants was incomplete and was discarded; therefore, the study sample consisted of $430 \mathrm{HSAs}$, which is high and can be regarded as acceptable. According to the sociodemographic characteristics of the study participants, $50.2 \%$ were male, while $49.8 \%$ were female (table 2). The data were approximately normally distributed by an

Table 1 Indicating variables and their KMO and Bartlett's test results

\begin{tabular}{llrrl}
\hline & & \multicolumn{3}{l}{ Bartlett's test } \\
\cline { 3 - 5 } Variable & KMO & \multicolumn{1}{l}{$\mathbf{2}$} & df & P value \\
\hline Role ambiguity & 0.755 & 1380.10 & 28 & $\mathrm{P}<0.001$ \\
Role conflict & 0.647 & 515.11 & 21 & $\mathrm{P}<0.001$ \\
Role overload & 0.776 & 967.19 & 36 & $\mathrm{P}<0.001$ \\
Job satisfaction & 0.743 & 2147.41 & 190 & $\mathrm{P}<0.001$ \\
\hline
\end{tabular}

KMO, Kaiser-Meyer-Olkin. 
高量弯

产

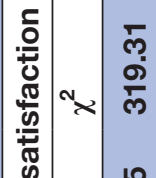

织

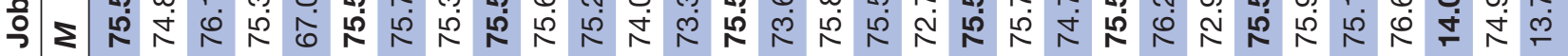

$\begin{array}{lll}\frac{0}{\pi} & & 0 \\ 2 & 0 \\ 2 & 0\end{array}$

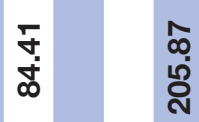

$\overline{8}$

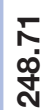

$\begin{array}{lll}8 & 8 & 9 \\ 8 & 8 & 0 \\ 0 & 0 & 0\end{array}$

ลั่

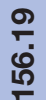

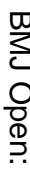

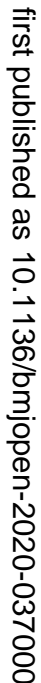

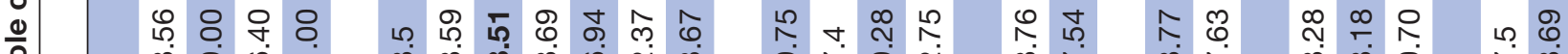

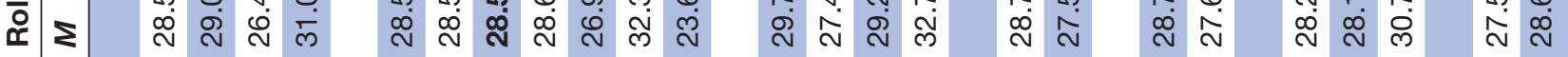

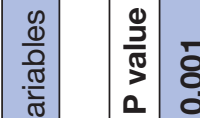

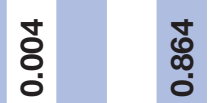

ర్ర

ชั

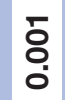

ริ

8

ํํำ ถึ

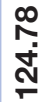

ลิ

م゚

รั

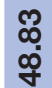

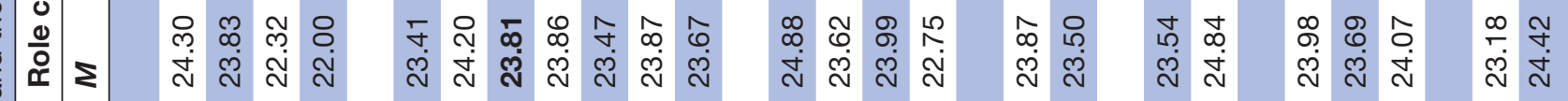
过

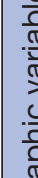

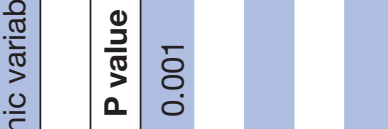

ฟั

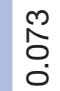

\begin{tabular}{lll}
$\stackrel{N}{0}$ & $\overline{0}$ \\
\hdashline & 0 \\
0
\end{tabular}

$\stackrel{0}{\stackrel{0}{w}}$

$\underset{\sigma}{\sigma}$

?

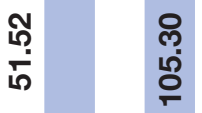

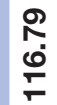

유ำ

올
ํㅗㅇ

ले

б.

กิ่

ז

กิ่

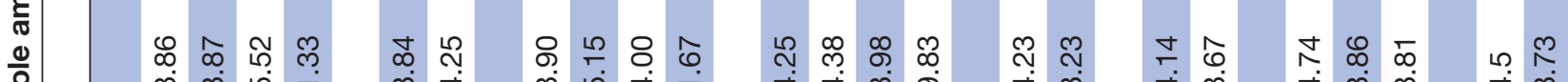

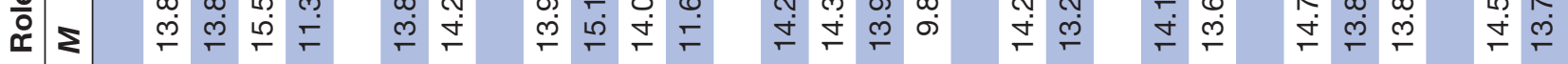

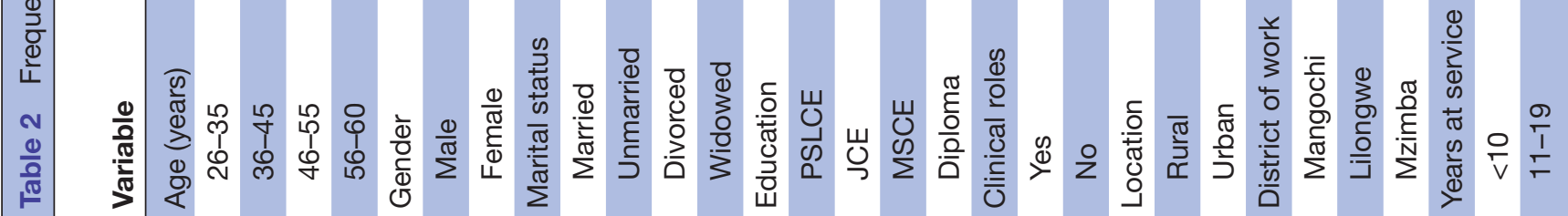




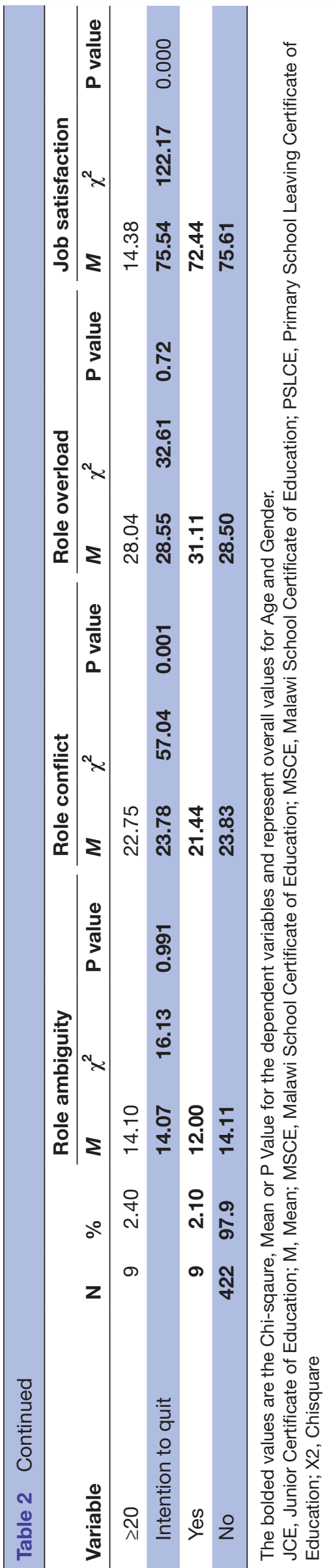

eyeball test used in determining the normality of data. The Q-Q ('Q' stands for quantile) plot results indicated all the data points had a linear tendency and lying on the diagonal. ${ }^{44}$ All the requirements for multicollinearity were met for me to conduct multiple linear regression analysis. This was achieved through collinearity statistics, which indicated no multicollinearity issue as all variables had tolerance above 0.84 .

\section{Relationships between sociodemographic variables and the} role stressors and job satisfaction

From table 2, highly significant relationships were observed between sociodemographic characteristics of the participants and the role stressors and job satisfaction. Age was significantly related to role ambiguity, role conflict, role overload and job satisfaction. Gender was significantly related to role ambiguity, role conflict and job satisfaction. However, insignificant associations were observed between gender and role overload.

Marital status was significantly related to role overload, and insignificant relationships were found with role ambiguity, role conflict and job satisfaction. Additionally, this study findings indicate that role overload was high among divorced women. Level of education was significantly related to role conflict, role overload and job satisfaction. Findings for role ambiguity and education level were however not significant. This means that education level was related to role conflict, role overload and job satisfaction. Moderately high role conflict levels were observed among the respondents with a primary school leaving certificate of education, role overload among participants with a diploma and job satisfaction among participants with a Junior Certificate of Education. The addition of new roles was significantly related to all the role stressors and job satisfaction.

Intention to quit is a reactionary measure that occur among employees that are stressed and dissatisfied in their work. Some employees when stressed usually resort to quitting their jobs. In this study, only two HSAs had the intention to quit, and statistically significant results were obtained with role conflict, while insignificant results were obtained with role ambiguity and role overload.

HSAs' work location either at a rural or urban area had some significant findings in this study. The HSAs working at either rural or urban areas are all similar in terms of training and nature of activities. Highly significant findings were found between working at either rural area or urban areas and the role stressors and job satisfaction (table 2). This study findings indicate that respondents in health facilities based in rural areas had high role ambiguity, role overload and job satisfaction compared with those in the cities (table 2). However, respondents in health facilities based in the urban area had high perception of role conflict compared with those in the rural area.

Furthermore, significant relationships were observed between years at service post with role ambiguity, role conflict and job satisfaction. This means that years at service post were related to role ambiguity, role 
Table 3 The means and SD of the dependent variables

\begin{tabular}{lllll}
\hline & Mean & SD & Observed range & Gold standard range \\
\hline RA & 1.76 & 0.74 & $0.86-4.88$ & $1.00-5.00$ \\
RC & 3.40 & 0.89 & $1.29-5.00$ & $1.00-5.00$ \\
RO & 3.18 & 0.94 & $1.00-5.00$ & $1.00-5.00$ \\
JS & 3.80 & 0.47 & $1.60-4.75$ & $1.00-5.00$ \\
\hline
\end{tabular}

JS, job satisfaction; RA, role ambiguity; RC, role conflict; $\mathrm{RO}$, role overload.

conflict and job satisfaction. HSAs who had served for a period range of 11-19 years had slightly high role conflict, while those with fewer than 10 years at work had slightly high role ambiguity compared with those in the other age ranges. However, satisfaction was high in those who had served for a period greater than 20 years (table 2).

\section{Role stressors and job satisfaction levels in HSAs}

From table 3, the overall role ambiguity mean score was $1.76(\mathrm{SD}=0.76)$ indicating that the HSAs had little role ambiguity. The overall role conflict mean score resulted in a mean score of $3.40(\mathrm{SD}=0.89)$ indicating that the HSAs had mild levels of role conflict. The overall role overload mean score was $3.18(\mathrm{SD}=0.94)$ indicating that the HSAs had moderate levels of role overload. The minimum and maximum range for the role stressors' mean scores had a range of $1.00-5.00$. The overall job satisfaction mean score was $3.80(\mathrm{SD}=0.47)$ indicating that the HSAs had high job satisfaction level. The HSAs in this study were highly satisfied with their job.

\section{Task frequency}

In this study, vaccination and growth monitoring came out clearly as frequently carried out tasks by the respondents. Tasks that were rarely performed were salt testing for iodine and sputum collection and examination (see figure 1).

\section{Correlations between HSA tasks and the dependent variables}

From table 4, out of the 17 HSAs tasks, nine had significant relationships with the role stressors and job satisfaction, while four had insignificant relationships and for three tasks (sanitation promotion, IEC and vaccination) their correlation failed to complete due to the presence of constants as all the respondents had similar responses with nothing to correlate. The tasks that were negatively significantly related to role ambiguity were antenatal care (ANC) and postnatal care (PNC) visits, family planning, drug dispensing and nutrition. The tasks that were positively correlated with role ambiguity were salt testing for iodine and growth monitoring promotion (GMP). In terms of role conflict, salt testing was negatively correlated with role conflict. Tasks that were positively significantly related to role conflict were GMP and home-based care, drug dispensing, HIV testing service (HTS), malaria rapid diagnosis testing and nutrition. Tasks that were

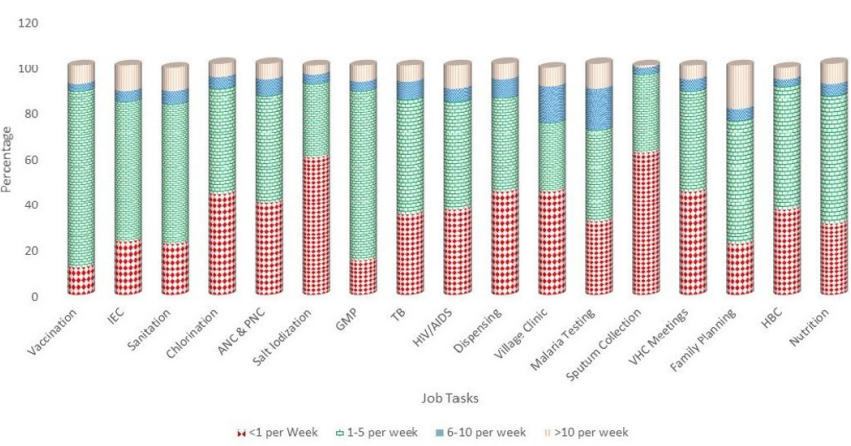

Figure 1 HSAs' tasks frequencies. Data are the percentage indicating the frequency of HSAs' job tasks. For clarity $<1$ per week indicates rarely performed tasks when mentioned by $50 \%$ or more of the respondents, $<1$ per week when mentioned by $80 \%$ or more means very rarely performed, tasks performed 1-5 times per week are frequently conducted when mentioned by $70 \%$ of the respondents, tasks performed 6-10 times per week and more than 10 times per week are very frequently conducted when mentioned by over $70 \%$ of the respondents. ANC, antenatal care; GMP, growth monitoring promotion; HBC, home-based care; HSAs, health surveillance assistants; PNC, postnatal care; VHC, village health committee; IEC, information, education and communication, .

positively correlated with role overload were GMP, village health committee (VHC) meetings and HTS while those that were significantly positively related to job satisfaction were sputum collection and examination, VHC meetings and family planning.

\section{Relationships between the role stressors and job satisfaction}

As shown in table 5 , there was a significant negative relationship between role ambiguity and job satisfaction. This means that there was an association between role ambiguity and job satisfaction. There was a weak, negative and non-significant association between role conflict and job satisfaction. This means that there was no association between role conflict and job satisfaction in HSAs. In addition, there was a weak, negative and significant association between role overload and job satisfaction. This means that there was a negative association between role overload and job satisfaction in HSAs.

\section{Identification of factors for role stressors and job satisfaction through PCA \\ Role ambiguity}

From table 6 , three factors contributing to role ambiguity were extracted. The first factor explained $45.26 \%$ of the total variance, while all the three components explained $73.63 \%$ of the total variance. The extraction was done with a loading factor value of 0.70 where component 1 loaded on three items that reflected on the 'supervisor' with an eigenvalue of 3.62, component 2 loaded on three items that reflected on 'role clarity' with an eigenvalue of 1.27 and component 3 loaded on one item that reflected on 'work guidelines' with an eigenvalue of 1.00. 
Table 4 Correlations between HSA tasks and the dependent variables

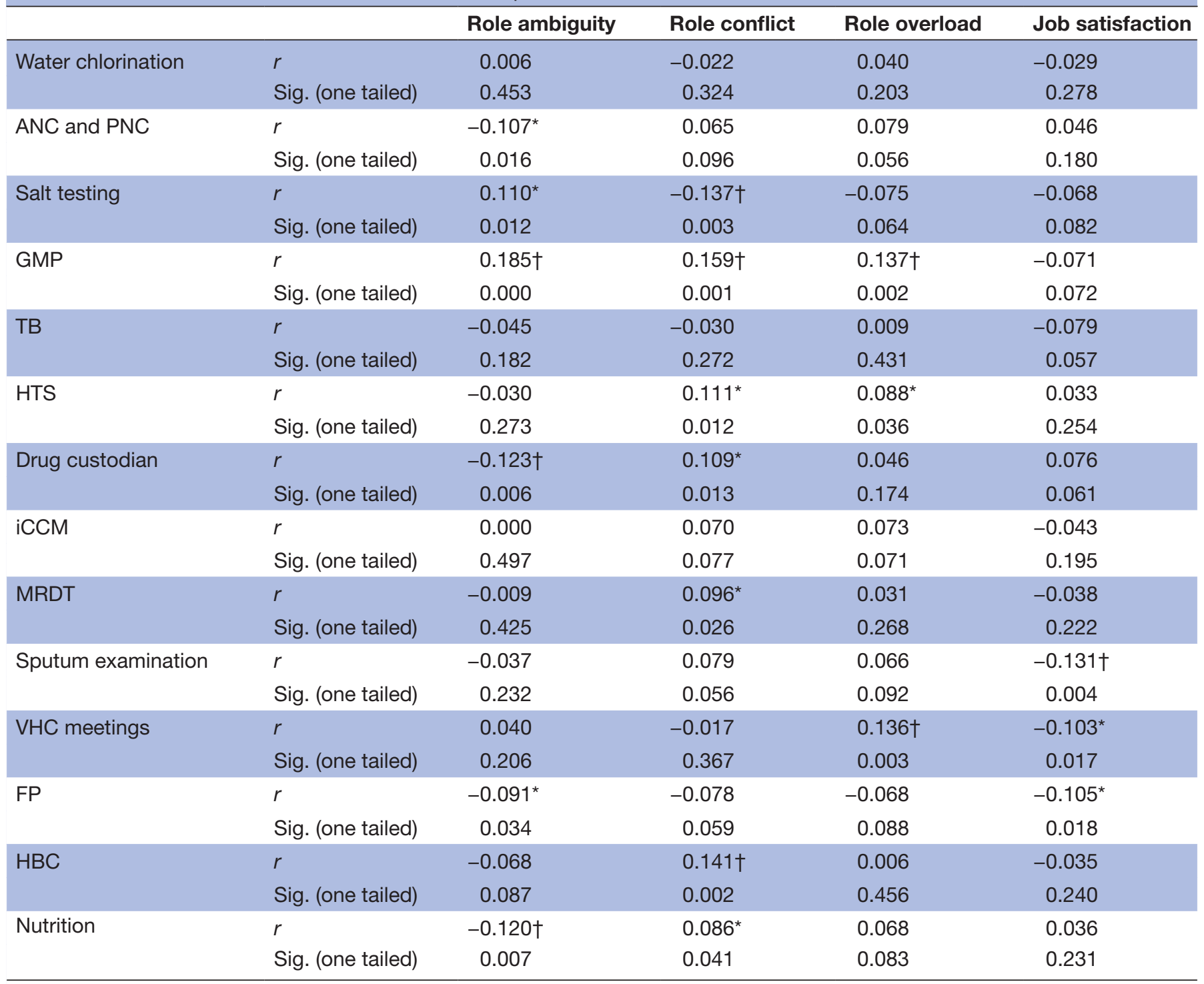

${ }^{*}$ Correlation is significant at the 0.05 level.

†Correlation is significant at the 0.01 level.

ANC, antenatal care; FP, Family Planning; GMP, growth monitoring promotion; HBC, home-based care; HSA, health surveillance assistant; HTS, HIV testing service; ICCM, Intergrated Community Case Management; MRDT, malaria rapid diagnosis testing; PNC, postnatal care; $\mathrm{VHC}$, village health committee.

Role conflict

From table 6, two factors contributing to role conflict were extracted after conducting the PCA analysis. The first factor explained $33.19 \%$ of the total variance, while all the two factors combined explained $54.64 \%$ of the total variance. The extraction was carried out with a factor loading value of 0.70 and loaded three items on component 1 with an eigenvalue of 2.32 that reflected on 'incompatibility' and two items on component 2 with an eigenvalue of 1.50 that reflected on 'time and person values'.

Role overload

From table 6 , three factors contributing to role overload were extracted after conducting the PCA. The first factor explained $45.26 \%$ of the total variance, while all the three factors when combined explained $63.04 \%$ of the total variance. In this analysis, component 1 loaded two items, component 2 loaded two items and component 3 loaded one item. Component 1 items reflected on issues of 'time pressure' with an eigenvalue of 3.37 , while component 2 reflected on the issue of 'task overload' with an eigenvalue of 1.20 and component 3 reflected on issues of 'work prioritisation' with an eigenvalue of 1.11.

\section{Job satisfaction}

From table 6, six factors contributing to job satisfaction were extracted after conducting the PCA. The first factor explained $23.31 \%$ of the total variance, while all the six factors explained $58.84 \%$ of the total variance. The six 
Table 5 Relationships between the role stressors and job satisfaction

\begin{tabular}{llccll}
\hline & & RA & RC & RO & JS \\
\hline RA & $R$ & 1 & & & \\
& P value & & & & \\
RC & $r$ & $-0.247^{*}$ & 1 & & \\
& P value & 0.01 & & & \\
RO & $r$ & $-0.097 \dagger$ & $-0.307^{*}$ & 1 & 1 \\
& P value & 0.022 & 0.01 & & \\
JS & $r$ & $-0.238^{*}$ & -0.004 & $-0.159^{*}$ & 1 \\
& P value & 0.01 & 0.472 & 0.01 & \\
\hline
\end{tabular}

${ }^{*}$ Correlation is significant at the 0.01 level (one tailed). †Correlation is significant at the 0.05 level (one tailed). $\mathrm{JS}$, job satisfaction; RA, role ambiguity; RC, role conflict; RO, role overload.

factors were advancement, work conditions, supervision, ability utilisation, social service and activity.

\section{Multiple linear regression analysis with role stressors and job} satisfaction among HSAs $(n=430)$

Multiple linear regression results have indicated that some sociodemographic variables, job tasks and factors identified in PCA were identified as predictors of role stressors and job satisfaction. In terms of role ambiguity, model 1 demonstrated that no variable was significantly correlated

\begin{tabular}{llll}
\hline $\begin{array}{l}\text { Table } 6 \\
\text { stressors identified during PCA }\end{array}$ & \multicolumn{4}{l}{ Summarised results indicating factors for role } \\
\hline Variable & EV & $\%$ of var & Cum. tot. \\
\hline Role ambiguity & & & \\
$\quad$ Supervisor & 3.62 & 45.26 & 30.3 \\
\hline Role clarity & 1.27 & 15.84 & 60.05 \\
\hline Guidelines & 1 & 12.53 & 73.63 \\
\hline Role conflict & & & \\
\hline Incompatibility & 2.32 & 33.19 & 32.78 \\
\hline Time and personal values & 1.5 & 54.64 & 54.64 \\
\hline Role overload & & & \\
\hline Time pressure & 3.37 & 45.26 & 26.03 \\
\hline Task overload & 1.2 & 21.36 & 47.39 \\
\hline Prioritisation & 1.11 & 15.65 & 63.04 \\
\hline Job satisfaction & & & \\
\hline Advancement & 4.66 & 23.31 & 12.39 \\
\hline Work conditions & 1.88 & 9.41 & 24.59 \\
\hline Supervision & 1.64 & 8.20 & 34.97 \\
\hline Ability utilisation & 1.42 & 7.10 & 43.43 \\
\hline Social service & 1.09 & 5.43 & 51.43 \\
\hline Activity & 1.08 & 5.39 & 58.84 \\
\hline Cum. & & \\
\hline
\end{tabular}

Cum. tot., cumulative total; EV, eigenvalue; \% of var, percentage of variance. to role ambiguity. Model 2 place of work (either at a district hospital or health centre) was significantly correlated to role ambiguity. Model 3, place of work and the job tasks of salt iodisation and GMP were significantly corelated to role ambiguity. In the full model, model 4 , job tasks such as ANC/PNC visits and GMP and all the factors identified from PCA (supervisor, role clarity and guidelines) were significantly correlated to role ambiguity (table 7 ).

In terms of role conflict, model 1 demonstrated no single variable was significantly correlated to role conflict. Model 2 demonstrated that age and place of work were significantly correlated to role conflict. In model 3, age, education level, place of work and some job tasks for HSAs such as salt iodisation, GMP and VHCs were significantly correlated to role conflict. Overall, model 4 demonstrated years at service post, salt iodisation task and all the factors identified from PCA (intrasender role conflict and intrarole and person role conflict) were significantly correlated to role conflict (table 8).

In terms of role overload, in model 1, education level was significantly correlated to role overload. In model 2 , no variable was significantly correlated to role overload. In model 3, the ANC/PNC task was significantly correlated to role overload. Overall, in model 4, the clinical role, the ANC/PNC visits task and the identified PCA factors (time pressure, task overload and work prioritisation) were significantly correlated to role overload (table 9).

In terms of job satisfaction, Model 1, none of the variables were significantly correlated to job satisfaction. In model 2, location (either rural or urban) and years at service post were significantly correlated to job satisfaction. In model 3, location, years at service post, and the job tasks of salt iodisation, HTS and family planning were significantly correlated to job satisfaction, and overall, in model 4, place of work, location, years at service post and all the factors identified from PCA (advancement and recognition, work conditions and organisation policies, supervision, ability utilisation, social service and activity) were significantly corelated to job satisfaction (table 10).

\section{DISCUSSION}

To our knowledge, this study was the first to explore role stressors and job satisfaction of HSAs in Malawi and to determine the role of the sociodemographic and workrelated variables on the relationship between the role stressors and job satisfaction. This study has contributed to the body of knowledge by providing empirical evidence to decision makers in Malawi and other countries facing similar challenges of workforce shortages and need to learn about the role stressors and job satisfaction among CHWs.

\section{Relationships between the role stressors and job satisfaction}

This study has revealed significant findings between role ambiguity and role overload and job satisfaction. Role ambiguity was negatively significantly related with job satisfaction, while role overload was negatively significantly 


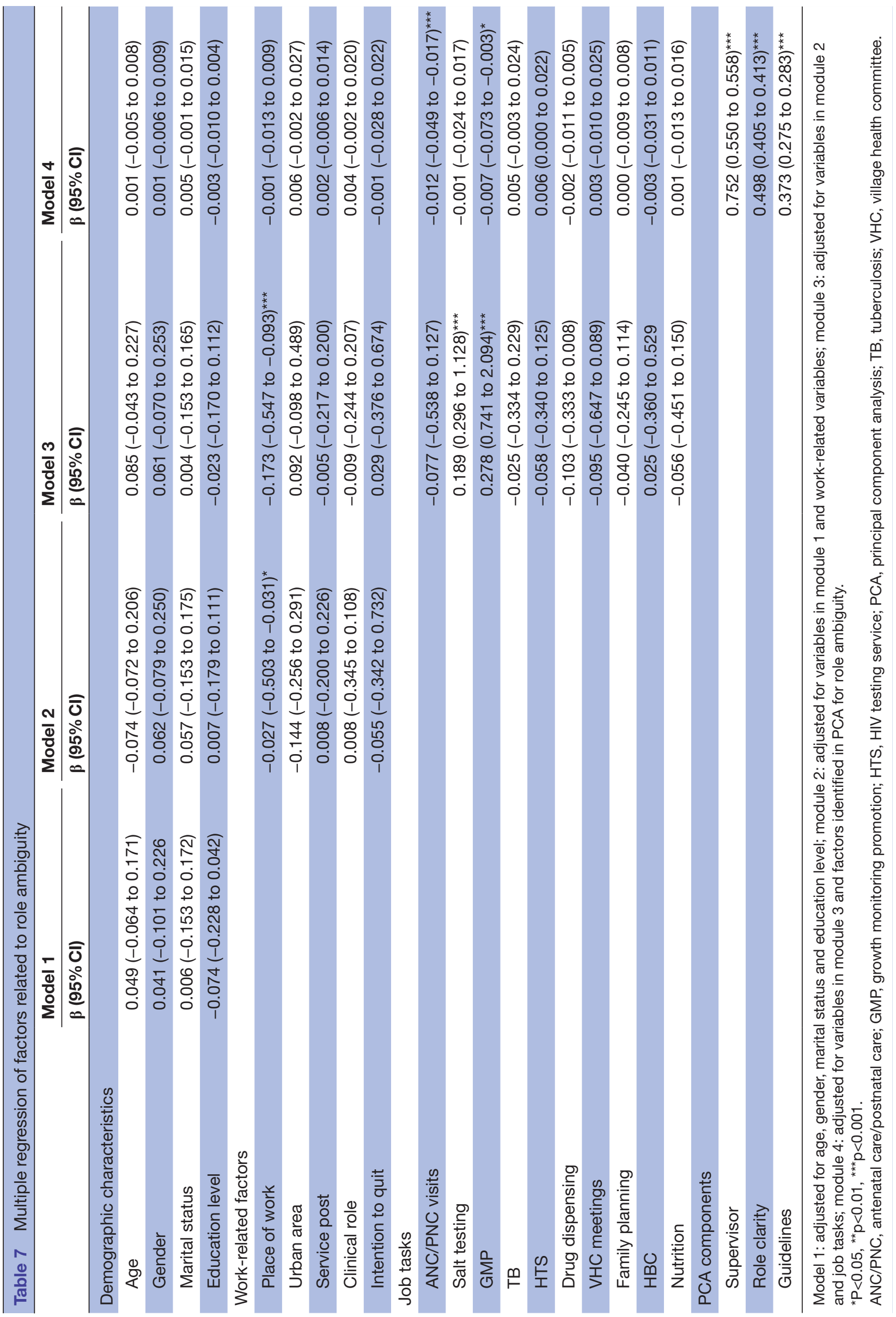




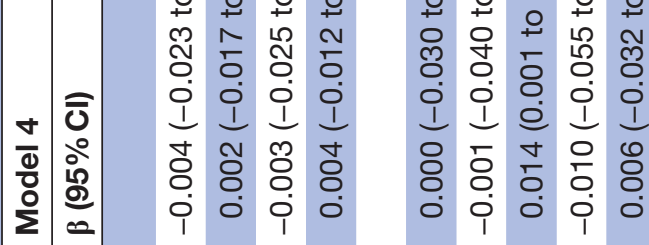

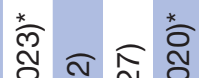
ㅇำ సิ กิ ○ 0 웅 స్

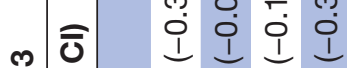

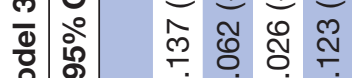

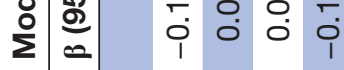

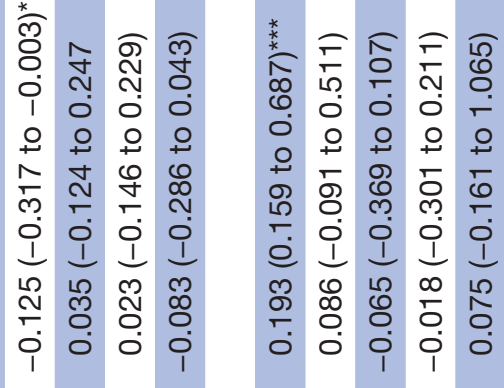

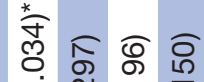

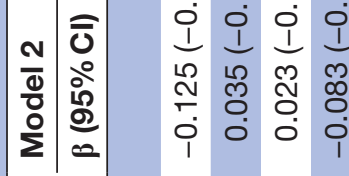

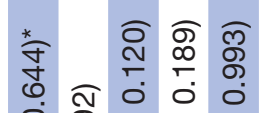

$\begin{array}{llll}0 & 0 \\ 0 & 2 & 0 & 0 \\ 0 & 0 & 0 & 0 \\ 0 & 0 & 0 & 0\end{array}$

ले

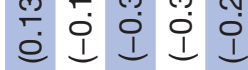

व

テ.

药

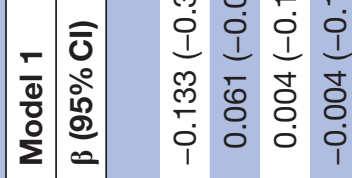

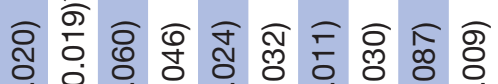

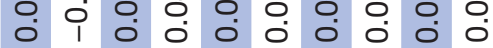

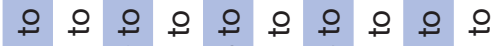

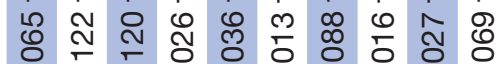

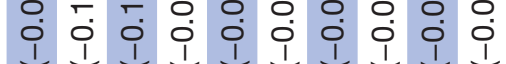

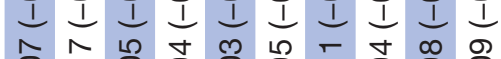

¿ิ

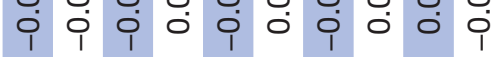

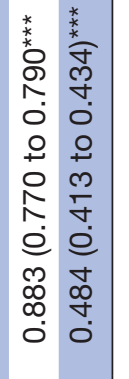

$\stackrel{0}{3}$

$\frac{10}{8}$

$\underset{\vec{F}}{\stackrel{\vec{S}}{+}}$

음

$\frac{\overline{0}}{\bar{D}}$

赵

$\vec{\circ}$

$\overrightarrow{\vec{\omega}}$

응.

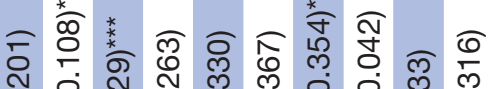

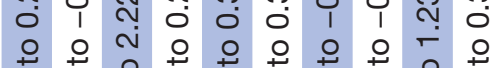

N

సิ

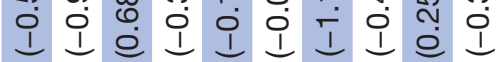

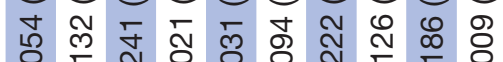

i 


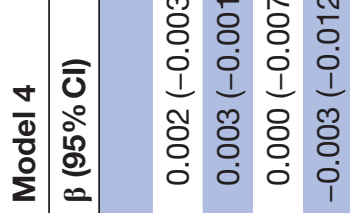

โ

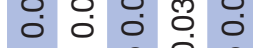
아 아 우웅 늉 $\begin{array}{llll}1 & 1 & 1 & 1 \\ 0 & 0 & 0 & 0 \\ 0 & 1 & 0 & 1\end{array}$

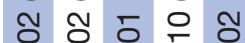

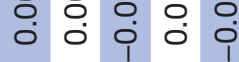

ชิ ภे กิ กิ

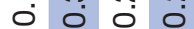
웅ㅇ 우 虫 m Uิ $\begin{array}{llll}1 & 0 & 0 & 0 \\ 0 & 1 & 1 & 1\end{array}$ ฮ

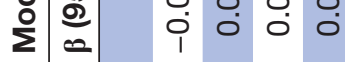

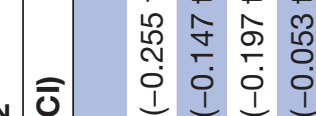
ר

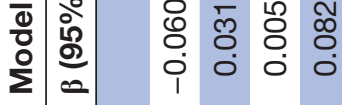

ชิ $\widehat{\mathcal{A}}$ ¿ $\circ$ ० 0 o 웅ㅇㅇㅇ

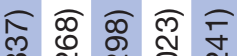

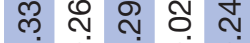
० 0 0 0 o 0 아 아 우아 운 学 守 $\begin{array}{lllll}1 & 0 & 0 & 0 \\ 0 & 1 & 1 & 1 & 1 \\ 0 & 1 & 1 & 0\end{array}$ ำ 눙 508 o i 0 i i

m d্ল

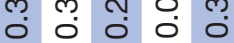

$\circ$ 융ㅇ

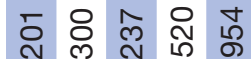

$\begin{array}{lllll}1 & 0 & 0 & 0 & 0 \\ 1 & 1 & 1 & 1\end{array}$

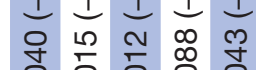

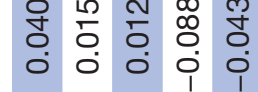

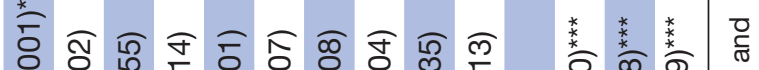

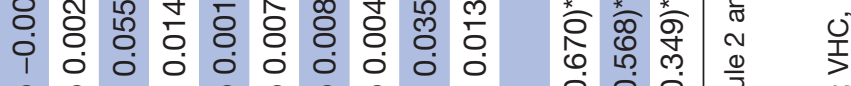

우 우 우 우 우 우 우 오 우 우

กิ

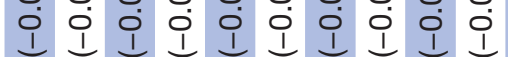

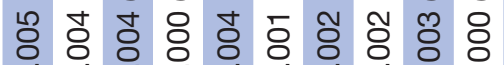

i $\begin{aligned} & 1 \\ & 0\end{aligned}$

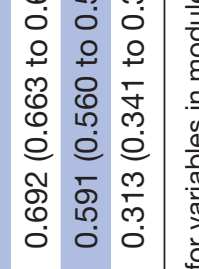

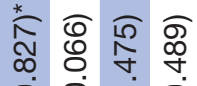

o 0 व

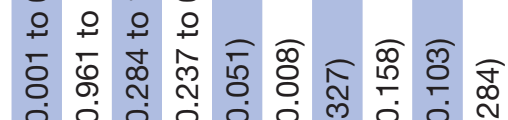

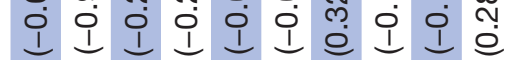

六 ○.

8

ज

음

吕

$\overrightarrow{0}$

$\vec{\omega}$

욱

웅

กิ

용

Ф్ర

은

$\vec{A}$

옹

ำ

$\sum_{\bar{D}}$

\%

을

룽

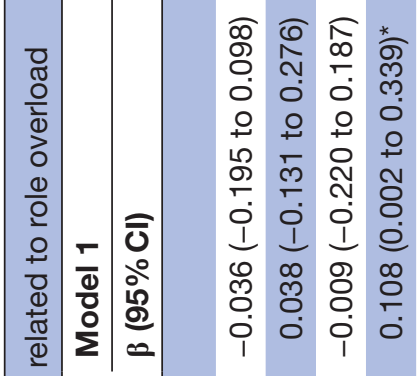

ᄒั

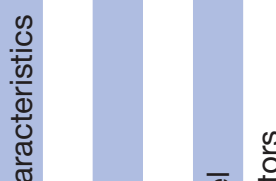

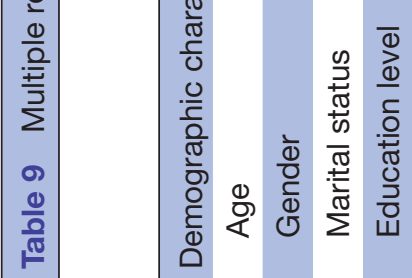

蒙 步

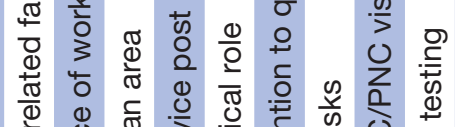

o 0 क

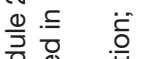

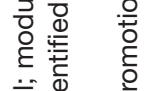

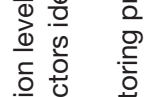

矢宽

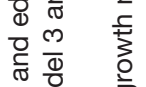

营 $\stackrel{0}{\subseteq} \sum_{0}^{\infty}$

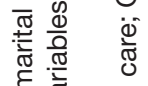

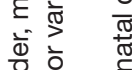

क人

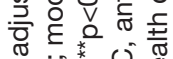

\% is

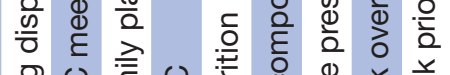

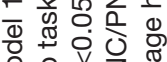

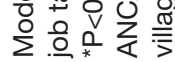




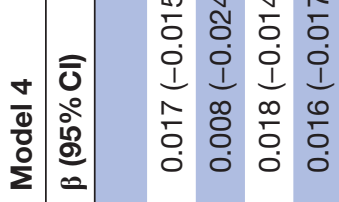

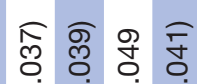

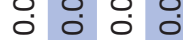
$\circ$ 웅ㅇ

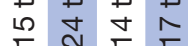

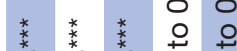
范 o 0 o $\frac{10}{1} \frac{m}{1} \frac{m}{1} \frac{n}{1} \frac{1}{1}$ นึ้ i 1 i 1 i
ত্ল ¿.

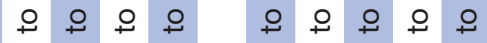
융 융두 즁

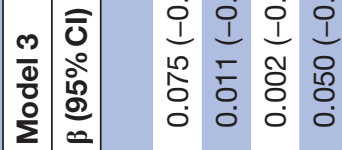

단ㄷำ

o

००

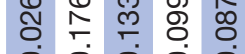

- 1 i i 10
ฟิ

o 0 o

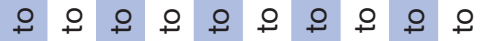

1. ल i 00 i

응

ชิ ชิ

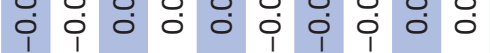

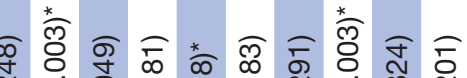

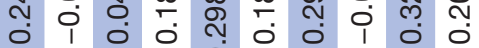

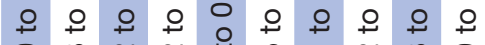

৫ $\begin{array}{lllllllll}1 & 1 & 1 & 0 & 0 & 0 & 0 & 0 & 0 \\ 0 & 1 & 0 & 1 & 1 & 1 & 1 & 1\end{array}$

N O

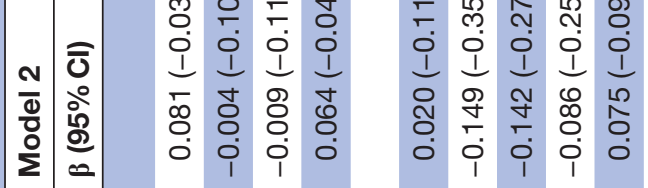

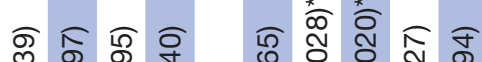

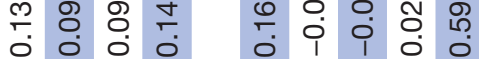

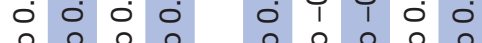
오오 우 오우우

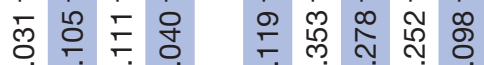

สิธิ์

0

앙

囟

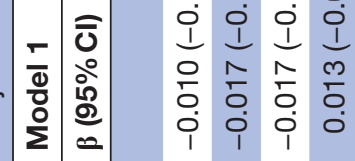

8

$\frac{\pi}{0}$

क

荌 
related to job satisfaction. The finding is consistent with the findings of earlier studies conducted in other professions. ${ }^{45}$ However, role conflict was negatively insignificantly related to job satisfaction and for this reason we will only discuss the findings of role ambiguity, role overload and job satisfaction. Other studies conducted in other professions have reported similar findings. ${ }^{46}$ Although the levels of role ambiguity and role overload are lower and mild in HSAs, there is need by government to initiate measures to control these role stressors in order to ensure continued job satisfaction and good work performance among HSAs.

\section{Role overload}

In terms of role overload, the most important factor was time pressure. This finding is in agreement with Davis $e t$ $a l,{ }^{47}$ who found CHWs working under pressure to provide services related to their new roles. Evidence from literature suggests that when employees are overloaded with tasks they tend to prioritise tasks they feel are important. ${ }^{48}$ For example, tasks such as immunisation of children are considered important and this is why in this study, vaccination and growth monitoring promotion were frequently conducted about 1-5 times per week by over $70 \%$ of the respondents.

Additionally, the addition of clinical tasks to existing HSAs' job tasks is related to role overload. Other literature evidence is in support of this assertion as similar findings have been reported elsewhere following introduction of additional roles. ${ }^{49}$ Other literature evidence suggests the introduction of clinical roles among HSAs in Malawi has expanded their role and divided their time and attention. It is further argued in the literature that HSAs spend most of their time at the health facility unlike at the community. ${ }^{50}$ Furthermore, HSAs are engaged in certain roles, of which some are incompatible with their traditional roles. ${ }^{51}$ Arguably, the changes made to the HSAs' roles require new skills, sufficient time and quality supervision for them to be effectively delivered at the community level. ${ }^{51}$ Previously, the HSAs were only performing a few preventive health tasks such as water, sanitation and hygiene (WASH), immunisations and growth monitoring. ${ }^{52}$ Increased health demands at the community level and the critical shortage of health workers have necessitated the addition of new roles to the HSAs. ${ }^{53}$ Evidence from the literature suggests role stressors among employees are likely to contribute to lower job satisfaction and poor job performance if mitigation measures are not put in place. ${ }^{54}$ Therefore, it is imperative for Malawi Ministry of Health to consider this when adding new roles to HSAs.

Furthermore, it is reported that the addition of new clinical roles to the CHWs has affected their traditional roles to the extent that some of their traditional roles have been forgotten. ${ }^{55}$ The tasks that were identified as predictors for role overload were growth monitoring and HTS. However, considering the significant health gains that the Ministry of Health in Malawi has made in achieving four out of eight millennium development goals (MDGs) of which three are health related: reducing child mortality, combating HIV and AIDS, malaria and other diseases, ${ }^{56}$ this task shifting is necessary and relevant for the Malawi Ministry of Health. Much of this achievement is attributed to HSAs' work at the community level. Looking at these achievements, their positive health outcomes and the growing demands for healthcare, it is important to continue with the task shifting but with some regulation. Although the guidelines for HSAs' task shifting are available, it would be important if the Ministry of Health went further to introduce an independent body for HSAs' task regulation such as the Medical Council of Malawi or the Nurses Council of Malawi.

56

\section{Role ambiguity}

The most important factor for role ambiguity in this study was the supervisor. Additionally, the HSAs curative tasks were negatively related to role ambiguity. These results suggest that the HSAs' supervision and the introduction of clinical roles have a contribution towards HSA role ambiguity.

The HSAs in Malawi are well known for being poorly supervised ${ }^{57}$ Evidence from the literature suggests supervision should be done regularly and that the supervisors should be experts in the field and should be able to provide new knowledge and actively engage the supervisees during supervision. ${ }^{58}$ Currently, the AEHOs are considered as the principal supervisors for the HSAs and are supported by senior HSAs, clinical officers and community nurses. In light of the expansion of the HSAs' role, supervision really needs to be given a priority as the country has a critical shortage of clinicians and nurses to provide the requisite supervision. ${ }^{59}$ Some of the barriers to effective supervision of CHWs that have been reported include travel expenses and logistics for face-to-face interaction meetings with the CHWs, lack of appropriate supervisory tools, inadequate understanding of CHW roles, and the poor general perception managers have towards CHWs supervision, lack of supervisory training and resources to provide a conducive climate for CHWs and their oversight due to some existing bureaucracies. ${ }^{60}$

Additionally, the place of work, either at a health centre or district hospital, had a role in terms of role ambiguity where HSAs at a health centre had high role ambiguity compared with their colleagues at the district hospital. This may be related to the supervision factor earlier alluded to. Evidence from the literature suggests role ambiguity arises when trainees are unsure of supervisory expectations for their performance or evaluation. Further evidence indicates that in Malawi, there are challenges with the supervision of HSAs due to human resources shortage, lack of financial resources and lack of transportation for mobility by supervisors. ${ }^{61}$ 


\section{Job satisfaction}

In terms of satisfaction, extrinsic factors (supervision, work conditions and organisation policies) and intrinsic factors (advancement and recognition, ability utilisation, social service and activity) were identified as factors for HSAs job satisfaction. The intrinsic factor of 'advancement and recognition' was identified as the major predictor for job satisfaction. This finding is consistent with the findings of other researchers where compensation and advancement have been identified as the most important predictors for job satisfaction. ${ }^{62-65}$ Similarly, the HSAs in Malawi are lacking good compensation and a clear career structure for their advancement, which is demotivating and dissatisfying considering that the majority of them work in very rural and remote areas where communication is a challenge. The current practice for HSAs advancement is that they have to get back to school and improve their grades and later enrol in a college to train either as a nurse or medical assistant Ntopi ${ }^{66}$ In light of this, there is need to understand more about their needs and that it is important that they are fully supported in order to ensure their optimisation and productivity to achieve improved health outcomes. ${ }^{67-7071}$ Bacotic $^{71}$ suggests job satisfaction should be looked at as key to the retention of employees. It is quite surprising to note that in government, there are other cadres with short duration of training as HSAs but are considered for promotion within their career structure without going back to school. It is therefore important that government should look at these critical issues to ensure that HSAs remain motivated and satisfied in their work. This study therefore urges policy makers at the Ministry of Health to review the community health strategy to ensure that HSAs have a clear career structure for advancement.

\section{Sociodemographic variables and the role stressors and job satisfaction}

In addition to the predictors discussed above, sociodemographic characteristics such as work location and years at service post were significantly associated with HSAs role stressors and job satisfaction.

First, HSAs' work location (either rural or urban) was significantly related to role ambiguity and job satisfaction. HSAs in rural areas had slightly high role ambiguity, role overload and job satisfaction levels compared with those in urban areas. This finding is in agreement with findings of another study in India on impact of job stress on urban and rural employees, which found location had an impact on the job stress of employees. ${ }^{72}$

The role ambiguity and role overload in HSAs might be explained by the fact that many HSAs are deployed in rural areas, in health centre catchment areas, where they are likely to experience challenges in supervision compared with their colleagues in urban area. However, this finding is inconsistent with the findings of earlier studies conducted in other professions that found no significant associations based on location (urban, suburban and rural settings). ${ }^{73}$ Additionally, work location was related to job satisfaction where the HSAs working in rural areas were slightly more satisfied than their colleagues in urban area. This finding is consistent with findings of Liu $e t a l^{74}$ who found that rural health workers in 11 western provinces of China with slight job satisfaction.

Second, HSAs' years at service post were significantly related to job satisfaction. This finding is consistent with findings from earlier studies conducted on job satisfaction where they found years at service post (tenure) had a relationship with job satisfaction. ${ }^{75}$

Third, gender was significantly related to role overload. This finding is consistent with the finding by Duc et $a l^{76}$ who found that gender had significant differences in the variances of the employees at a Bank for Investment and Development of Vietnam in Quangnam. Female employees' lives in Malawi is divided between home and work as they have to fulfil both familial and work obligations. However, other literature has found that there is no significant relationship between gender and role overload. ${ }^{77}$

In summary, the findings of this study have indicated that sociodemographic variables of HSAs have a role to play on their role stressors and the job satisfaction of HSAs. Therefore, it is important for Government of Malawi and all that are involved in HSAs' deployment to take note of the effect of these sociodemographic variables.

\section{Limitations}

One of the major limitations of this study is that it is a cross-sectional study and its results cannot institute causality among the relationships established.

\section{CONCLUSION}

Considering that some HSAs' tasks are correlated to role stressors, it is important that they should be addressed as a matter of priority. If mitigation measures are not initiated, the role stressors would very likely contribute to low performance at work and lower job satisfaction among HSAs. Additionally, stress conditions such as depression, dissatisfaction, anxiety and tension would arise. ${ }^{78}$ Therefore, there is an urgent need by the authorities and partners to join hands to address these role stressors for the HSAs to continue enjoying high job satisfaction and good performance at work. This study, therefore, would like to recommend that government should introduce measures that would control role stressors among HSAs. This study, therefore, proposes to government to introduce an independent regulatory body that would regulate HSAs' tasks in Malawi. Additionally, supervision of HSAs should be intensified to overcome the role stressors. Since the HSAs role is broader than the roles of other health cadres, it would be imperative to adopt an integrated approach towards the supervision of HSAs. This study, therefore, would like to propose interprofessional supervision (IPS) as an approach for the effective supervision of the HSAs in order to enhance HSAs' supervision in Malawi. IPS involves supervision by supervisors from different professional disciplines. ${ }^{79}$ This would help to 
address the challenges faced in the supervision of the HSAs, as their role is more interprofessional requiring supervisors from different health professional backgrounds. We propose this to start right at college by letting students from different professional background working and learning together in a class to ensure that effective teams for supervision are formed for greater performance and improved health outcomes.

Acknowledgements We, the authors, would like to thank all health surveillance assistants who participated in their study.

\section{Collaborators Simon Willard Ntopi}

Contributors SN designed the study and wrote the protocol (corresponding author), EC supervised the work of the research carried out and critically reviewed the manuscript for content and AM was responsible for statistical analysis. All authors contributed to critical revisions of the manuscript. All authors read and approved the final manuscript.

Funding The authors have not declared a specific grant for this research from any funding agency in the public, commercial or not-for-profit sectors.

Competing interests None declared.

Patient and public involvement Patients and/or the public were not involved in the design, or conduct, or reporting, or dissemination plans of this research.

Patient consent for publication Not required.

Ethics approval Ethical clearance was obtained from the College of Medicine Research Ethics Committee of Malawi (Certificate No. P.11/16/2054).

Provenance and peer review Not commissioned; externally peer reviewed.

Data availability statement The data that support the findings of this study are available from the corresponding author, upon reasonable request

Open access This is an open access article distributed in accordance with the Creative Commons Attribution Non Commercial (CC BY-NC 4.0) license, which permits others to distribute, remix, adapt, build upon this work non-commercially, and license their derivative works on different terms, provided the original work is properly cited, appropriate credit is given, any changes made indicated, and the use is non-commercial. See: http://creativecommons.org/licenses/by-nc/4.0/.

ORCID iD

Simon Ntopi http://orcid.org/0000-0001-8889-6064

\section{REFERENCES}

1 Hermann K, Van Damme W, Pariyo GW, et al. Community health workers for ART in sub-Saharan Africa: learning from experience-capitalizing on new opportunities. Hum Resour Health 2009;7:31.

2 Lehmann U, Sanders D. Community health workers: what do we know about them. State Evid programme act costs impact health outcomes using community health work. Geneva: World Health Organization, 2007: 1-42.

3 WHO. Country health profile Malawi. Geneva: Wolrd Health Organization, 2013.

$4 \mathrm{MoH} \mathrm{M}$. The health surveillance assistants, origins and current status. Ministry of Health, 2012

5 Perry HB, Zulliger R, Rogers MM. Community health workers in low-, middle-, and high-income countries: an overview of their history, recent evolution, and current effectiveness. Annu Rev Public Health 2014;35:399-421.

6 Smith S, Deveridge A, Berman J, et al. Task-shifting and prioritization: a situational analysis examining the role and experiences of community health workers in Malawi. Hum Resour Health 2014;12:24.

7 Ministry of Health. Guidelines for the management of task shifting to health surveillance assistants in Malawi. Ministry of Health, 2014.

8 Callaghan-Koru JA, Hyder AA, George A, et al. Health Workers' and Managers' Perceptions of the Integrated Community Case Management Program for Childhood Illness in Malawi: The Importance of Expanding Access to Child Health Services. Am J Trop Med Hyg 2012;87:61-8.

9 Gilroy KE, Callaghan-Koru JA, Cardemil CV, et al. Quality of sick child care delivered by health surveillance assistants in Malawi. Health Policy Plan 2013;28:573-85.
10 Kok MC, Muula AS. Motivation and job satisfaction of health surveillance assistants in Mwanza, Malawi: an explorative study. Malawi Med J 2013;25:5-11.

11 Smith S, Deveridge A, Berman J, et al. Task-shifting and prioritization: a situational analysis examining the role and experiences of community health workers in Malawi. Hum Resour Health 2014;12:24.

12 Al-Kahtani NS, Allam Z. A holistic approach to determine the relationship of Sociobiographical variables with role ambiguity and role conflict. Int Bus Manag 2016;10:2795-801.

13 Trayambak MS, Kumar P, Jha A. A conceptual study on role stressors, their impact and strategies to manage role stressors. IOSR J Bus Manag 2012;4:44-8.

14 Kahn RL, Wolfe DM, Quinn RP, et al. Organizational stress: studies in role conflict and ambiguity, 1964. Available: https://www.psc.isr. umich.edu/dis/infoserv/isrpub/pdf/Conflictandambiguity_2214_.PDF

15 Tarrant T, Sabo CE, Conflict R. Role conflict, role ambiguity, and job satisfaction in nurse executives. Nurs Adm Q 2010;34:72-82.

16 Yongkang Z, Weixi Z, Yalin $\mathrm{H}$, et al. The relationship among role conflict, role ambiguity, role overload and job stress of Chinese middle-level cadres. China Stud 2014;3:8-11.

17 Fakhry SF, El Hassan NAA. Causes and types of conflict and resolution strategies among nursing students: a comparative study between two cultures. J Am Sci 2011;7:808-15.

18 Katz D, Kahn RL. The social psychology of organizations. 2. New York: Wiley, 1978.

19 Fellows S, Kahn WA, Kessler EH. Role theory. In: Encyclopedia of management theory. 2nd edn. Thousands Oaks, CA: Sage Publications, 2016: 670-4.

20 Ozmete E, Hira T. Conceptual analysis of behavioral theories/models: application to financial behavior. Eur J Soc Sci 2011;18:386-404.

21 House RJ, Rizzo JR. Role conflict and ambiguity as critical variables in a model of organizational behavior. Organ Behav Hum Perform 1972;7:467-505.

22 Jayasuriya R, Bhadra J. The Moderating effect of compartmentalization on role consensus and work-life balance an investigation on managerial level employees in domestic commercial banks in Sri Lanka, 2014. Available: http://hdl.handle.net/123456789/ 1601

23 Surbhi S. Differences between Maslows and Herzberg's theories of motivation, 2017.

24 Lemeshow S, Hosmer D, Klar J, et al. Adequacy of sample size in health studies. England: John Wiley \& Sons Ltd, 1990.

25 Adams KA, Lawrence EK. Research methods, statistics, and applications. 2nd edn. Thousand Oaks, California: Sage Publications, 2018.

26 Rizzo JR, House RJ, Lirtzman SI. Role conflict and ambiguity in complex organizations. Adm Sci Q 1970;15:150-63.

27 Khan A, Yusoff RBM, Khan MM, et al. Psychometric analysis of role conflict and ambiguity scales in academia. Int Educ Stud 2014;7:104.

28 Palomino MN, Frezatti F. Role conflict, role ambiguity and job satisfaction: perceptions of the Brazilian controllers. Rev Adm 2016;51:165-81.

29 Reilly MD. Working wives and convenience consumption. J Consum Res 1982;8:407-18.

30 Pearson QM. Role overload, job satisfaction, leisure satisfaction, and psychological health among employed women. J Couns Dev JCD 2008;86:57-63

31 Bellizzi JA, Hite RE. Convenience consumption and role overload convenience. J Acad Mark Sci 1986;14:1-9.

32 Crouter AC, Bumpus MF, Head MR, et al. Implications of Overwork and Overload for the Quality of Men's Family Relationships. J Marriage Fam 2001;63:404-16.

33 Weiss DJ, Dawis RV, England GW. Manual for the Minnesota satisfaction questionnaire. Minn Stud Vocat Rehabil 1967.

34 Buitendach JH, Rothmann S. The validation of the Minnesota job satisfaction questionnaire in selected organisations in South Africa. SA J Hum Resour Manag 2009;7:1-8.

35 Burgel BJ, Wallace EM, Kemerer SD, et al. Certified occupational health nursing. job analysis in the United States. $A A O H N J$ 1997;45:581-91.

36 Mbambo S, Uys LR, Groenewald B. A job analysis of selected health workers in a district health system in KwaZulu-Natal. Part two: job analysis of nurses in primary health care settings. Curationis 2003;26:42-52.

37 Uys LR, Groenewald B, Mbambo S. A job analysis of selected health workers in a district health system in KwaZulu-Natal. Part one: job analysis of nurses in hospital settings. Curationis 2003;26:32-41.

38 Taber KS. The use of Cronbach's alpha when developing and reporting research instruments in science education. Res Sci Educ 2018;48:1273-96. 
39 Polit DF, Beck CT. Nursing research: generating and assessing evidence for nursing practice. 9th edn. Philadelphia: Wolters Kluwer/ Lippincott Williams \& Wilkins, 2014.

40 Naidoo S. Epidemiology: a research manual for South Africa. South Afr J Infect Dis 2015;30:200.

41 WHO. Process of translation and adaptation of instruments [Internet]. Available: https://www.who.int/substance_abuse/research_tools/ translation/en/

42 Julie P. Spss survival manual. McGraw-Hill Education, UK, 2013: 368.

43 Jolliffe IT. Discarding variables in a principal component analysis. I: artificial data. Appl Stat 1972;21:160-73.

$44 \mathrm{Kim} \mathrm{H}$-Y. Statistical notes for clinical researchers: assessing normal distribution (2) using skewness and kurtosis. Restor Dent Endod 2013;38:52-4.

45 Bozkurt V, Aytac S, Bondy J, et al. Job satisfaction, role overload and gender in Turkey. Sosyol Konf 2011:49-68.

46 Belias D, Koustelios A. Organizational culture and job satisfaction: a review. Int Rev Manag Mark 2014;4.

47 Davis DN, Lemani C, Kamtuwanje N, et al. Task shifting levonorgestrel implant insertion to community midwife assistants in Malawi: results from a non-inferiority evaluation. Contracept Reprod Med 2018;3:24.

48 Fontinha R, Easton S, Van Laar D. Overtime and quality of working life in Academics and nonacademics: the role of perceived work-life balance. Int J Stress Manag 2017;26:173-83.

49 Nasiripour A, Raeisi P, Shabanikia H. Occupational stress among rural health workers in Mashhad district, northeast Iran, 2009.

50 Martiniuk A, Smith S, Deveridge A, et al. Getting treatment and care to the last mile: analyzing the health surveillance assistant Cadre in Malawi. vol. Discussion paper 10. Waterloo, Canada: Africa InitiativeCentre for International Governance Innovation, 2014.

51 Kadzandira J. Task Shifting and its Effects on Health Surveillance Assistants in Malawi [PhD Thesis]. Dublin R Coll Surg Irel 2018.

52 Kadzandira JM, Chilowa W. The role of health surveillance assistants (HSAs) in the delivery of health services and immunisation in Malawi [Internet]. University of Malawi, Centre for Social Research, 2001. Available: https://www.unicef.org/evaldatabase/index 14066.html

53 Kok MC. Performance of community health workers: optimizing the benefits of their unique position between communities and the health sector, 2015

54 Ling AW, Bahron A, Boroh P. A study on role stress and job satisfaction among bank employees in Kota Kinabalu, Sabah. Int $J$ Res Manag Bus Stud 2014;1:19-23.

55 Olaniran A, Madaj B, Bar-Zev S, et al. The roles of community health workers who provide maternal and newborn health services: case studies from Africa and Asia. BMJ Glob Health 2019;4:e001388.

56 NSO MNSO. Malawi: MDG Endline survey, 2014: key findings. National Statistical Office, 2014.

57 Kok MC, Namakhoma I, Nyirenda L, et al. Health surveillance assistants as intermediates between the community and health sector in Malawi: exploring how relationships influence performance. BMC Health Serv Res 2016;16:164.

58 Hill Z, Dumbaugh M, Benton L, et al. Supervising community health workers in low-income countries--a review of impact and implementation issues. Glob Health Action 2014;7:24085.

59 Rodríguez DC, Banda H, Namakhoma I. Integrated community case management in Malawi: an analysis of innovation and institutional characteristics for policy adoption. Health Policy Plan 2015;30(Suppl 2):ii74-83.

60 Henry JV, Winters N, Lakati A, et al. Enhancing the supervision of community health workers with WhatsApp mobile messaging: qualitative findings from 2 low-resource settings in Kenya. Glob Health Sci Pract 2016;4:311-25.

61 Phuka J, Maleta K, Thomas M, et al. A job analysis of community health workers in the context of integrated nutrition and early child development. Ann N Y Acad Sci 2014;1308:183-91.

62 Bempah BSO. Determinants of job satisfaction among community health workers in the Volta region of Ghana. Pub Pol Admin Res 2013;3.

$63 \mathrm{Haq}$ Z, Iqbal Z, Rahman A. Job stress among community health workers: a multi-method study from Pakistan. Int J Ment Health Syst 2008;2:15.

64 Mpembeni RNM, Bhatnagar A, LeFevre A, et al. Motivation and satisfaction among community health workers in Morogoro region, Tanzania: nuanced needs and varied ambitions. Hum Resour Health 2015;13:44.

65 Kebriaei A, Moteghedi MS. Job satisfaction among community health workers in Zahedan district, Islamic Republic of Iran. East Mediterr Health J 2009;15:1156-63.

66 Ntopi SW. Impact of the expansion of the health surveillance assistants programme in Nkhatabay district of North Malawi, 2010. Available: http://hdl.handle.net/11394/2586

67 Baatiema L, Sumah AM, Tang PN, et al. Community health workers in Ghana: the need for greater policy attention. BMJ Glob Health 2016;1:e000141.

68 Sprague L. Community health workers: a front line for primary care? 2012.

69 Kironde S, Kahirimbanyi M. Community participation in primary health care $(\mathrm{PHC})$ programmes: lessons from tuberculosis treatment delivery in South Africa. Afr Health Sci 2002;2:16-23.

70 Mathauer I, Imhoff I. Health worker motivation in Africa: the role of non-financial incentives and human resource management tools. Hum Resour Health 2006;4:24.

71 Bacotic D. Relationship between job satisfaction and organizational performance. Econ Res-Ekon Istraz 2016;29:118-30.

72 Mazumdar H, Haloi N, Mazumdar M. Impact of job stress on urban and rural employees in Kamrup district, Assam (India): a physiological and psychological study. Arch Appl Sci Res 2011:3:377-82.

73 Cervoni A, DeLucia-Waack J. Role conflict and ambiguity as predictors of job satisfaction in high school Counselors. J Sch Couns 2011;9:n1.

74 Liu J, Zhu B, Wu J, et al. Job satisfaction, work stress, and turnover intentions among rural health workers: a cross-sectional study in 11 Western provinces of China. BMC Fam Pract 2019;20:9.

75 Dobrow Riza S, Ganzach Y, Liu Y. Time and job satisfaction: a longitudinal study of the differential roles of age and Tenure. $J$ Manage 2018;44:2558-79.

76 Duc T, Van N, Huu P, et al. Study on the factors affecting job satisfaction of employees at a bank for investment and development of Vietnam [Internet], 2015. Available: http://globalbizresearch.org/ Vietnam_Conference/pdf/VL558.pdf

77 Shoaib S, Mujtaba BG, Awan HM. Overload stress perceptions of public sector employees in Pakistan: a study of gender, age, and education in South Asia. Public Organ Rev 2018:1-14.

78 Duxbury L, Higgins C, Lyons S. The Etiology and Reduction of Role Overload in Canada's Health Care Sector, 2017.

79 Howard FM, Beddoe L, Mowjood A. Interprofessional supervision in social work and psychology in Aotearoa New Zealand. Aotearoa N Z Soc Work 2013;25:25-40. 